\title{
The Role Played by Mobile Phone Communication in the Diffusion of Dairy Goats Rearing in Kitui County, Kenya
}

\author{
Adongo J. $\mathbf{M}^{1}$, Wesonga P. $\mathrm{S}^{2, *}$, Serykhan N. $\mathbf{W}^{3}$ \\ ${ }^{1}$ World Vision International, Kenya \\ ${ }^{2}$ Department of Land Resource Management and Agricultural Technology, University of Nairobi, Kenya \\ ${ }^{3}$ Selco (BSA) Enterprise Limited, Kenya
}

Copyright $\bigcirc 2019$ by authors, all rights reserved. Authors agree that this article remains permanently open access under the terms of the Creative Commons Attribution License 4.0 International License

\begin{abstract}
The study investigated how farmers used mobile phone communication in dairy goat rearing to improve their livelihoods. The targeted farmers were widows, caregivers and orphans in Kitui County, Kenya. The two types of goats reared were Toggenburg and Galla. Sampling was done in two stages: proportional to get five clusters and random within a cluster to get a sample size of 100 respondents. The study found women consisted $71 \%$ of the sampled farmers. Forty two percent of farmers used their dairy milk for home consumption. Average goat milk production was 2.6 litres and retailed at KES70.00 per litre. The result suggests high adoption of mobile phone use as evidenced by eighty six percent of farmers who have owned their mobile phone for more than one year. Farmers $(69 \%)$ called Livestock extension officer and Veterinary officer, both of whom are instrumental in the general management and disease control of the dairy goats. Ownership and access of mobile phones have increased communication contacts amongst farmers, sellers, buyers and extension agents. We recommend that mobile phone communication be embedded in the programming of projects by policy makers.
\end{abstract}

Keywords Galla, Livelihood, Milk, Mpesa, Toggenburg

\section{Introduction}

The rapid spread of Information and Communication Technologies (ICT) in developing countries over the past decade offers a unique opportunity to transfer knowledge via private and public information systems. As of 2009, over half of thepopulations in sub-Saharan Africa, Asia and Latin America had access to mobile phone coverage, representing 60, 67 and 77 percent, respectively [1]. Mobile phone coverage has greatly exceeded investments in other infrastructures in these countries, namely,electricity, roads and landlines. Coinciding with this increase in mobile phone coverage has been an increase in mobile phone adoption, even in some of the world's poorest countries. As of 2008, there were about 4 billion mobile phone subscribers worldwide, with 374 million subscriptions in Africa, 1.791 billion in Asia and 460 million in Latin America. While initial adoption was primarily by the wealthy, urban and educated residents, mobile phones are currently being adopted by the rural poor in some of the world's poorest countries [2].

The diffusion of mobile phones into rural areas represents one of the most profound changes in rural Kenya and many other developing countries. Farmers, agricultural processors, and marketers have transitioned from a culture in which there was virtually no telephone service of any kind to one in which mobile phones are now widely utilized by farmers in the rural areas and markets. Rearing of dairy goats was introduced to Kitui County in the year 2007[3]. Toggenburg and Galla were the selected breeds because of their improved milk and meat yields.

\subsection{Problem Statement}

New technologies introduced to farmers have normally failed because extension officers do not have a convenient media to exchange required information.In many developing countries, such information has traditionally been provided via personal exchanges, radio and perhaps landlines and newspapers. Landlines are not readily available in most regions of Kitui County, and radio only provides price information for specific products and markets on a weekly basis. Mobile phone communication could be the solution to improve access and to use information foragricultural technologies.

The broad objective was to assess the role played by mobile phone communication in the diffusion of dairy goat rearing in Kitui County, Kenya.

The specific objectives were:

1. To determine proportion of farmers who own/have access to mobile phones 
2. To establish mobile phone applications (products) used by most dairy goat farmers in the course of dairy goat keeping

3. To identify constraints faced by dairy goat farmers as they used mobile phone communication in dairy goat rearing.

\subsection{Conceptual Frame Work}

This study aims to investigate the roles of Mobile phone communication in the diffusion of rearing of dairy goats.

The dairy goat farmer is at the Centre of the framework. The Livestock extension officer uses mobile phone to scout for the breeding stock and only take off with a sure destination in mind. This saves time and money and lowers the cost of scouting, thus saving the money for other uses. He uses mobile phone to mobilize dairy goat keepers to attend meetings, trainings and to prepare to receive their stock of goats. The feedback is instant as the farmers confirm that they have got the communication. He also gets reports on progress of the group and can make decisions without delay.

The farmers communicate to veterinary officer about sick animals and get assistance immediately. The time and money saved on transport to Veterinary office is spent somewhere else. Few animals die of disease attack. Buyers of milk and offspring easily contact the farmers for the commodities and get terms of sale at a much faster rate than through physical contact.

Farmers do mobile banking of their earnings through mobile phone money transfer services and pay for veterinary services and school levies. There is reduced risk of losing the money to thieves and robbers. Mobile phone communication between farmers and other stakeholders has facilitated a lot of information sharing which has enabled the group to move on as a team.

\subsection{Theoretical Framework}

According to Rogers [4], there are four main elements that influence the spread of a new idea. These are the innovation itself, communication channels, time, and a social system. Diffusion is the process by which an innovation is communicated through certain channels over time among the members of a social system. Individuals progress through 5 stages: knowledge, persuasion, decision, implementation, and confirmation. If the innovation is adopted, it spreads via various communication channels. During communication, the idea is rarely evaluated from a scientific standpoint; rather, subjective perceptions of the innovation influence diffusion. The process occurs over time. Finally, social systems determine diffusion, norms on diffusion, roles of opinion leaders and change agents, types of innovation decisions, and innovation consequences. In rearing of dairy goats, diffusion is about how, why and at what rate the technology of rearing of dairy goats has spread through the community of Kitui County from the first beneficiaries of the dairy goats to those farmers who acquired their own stock after understanding the benefits of the enterprise.

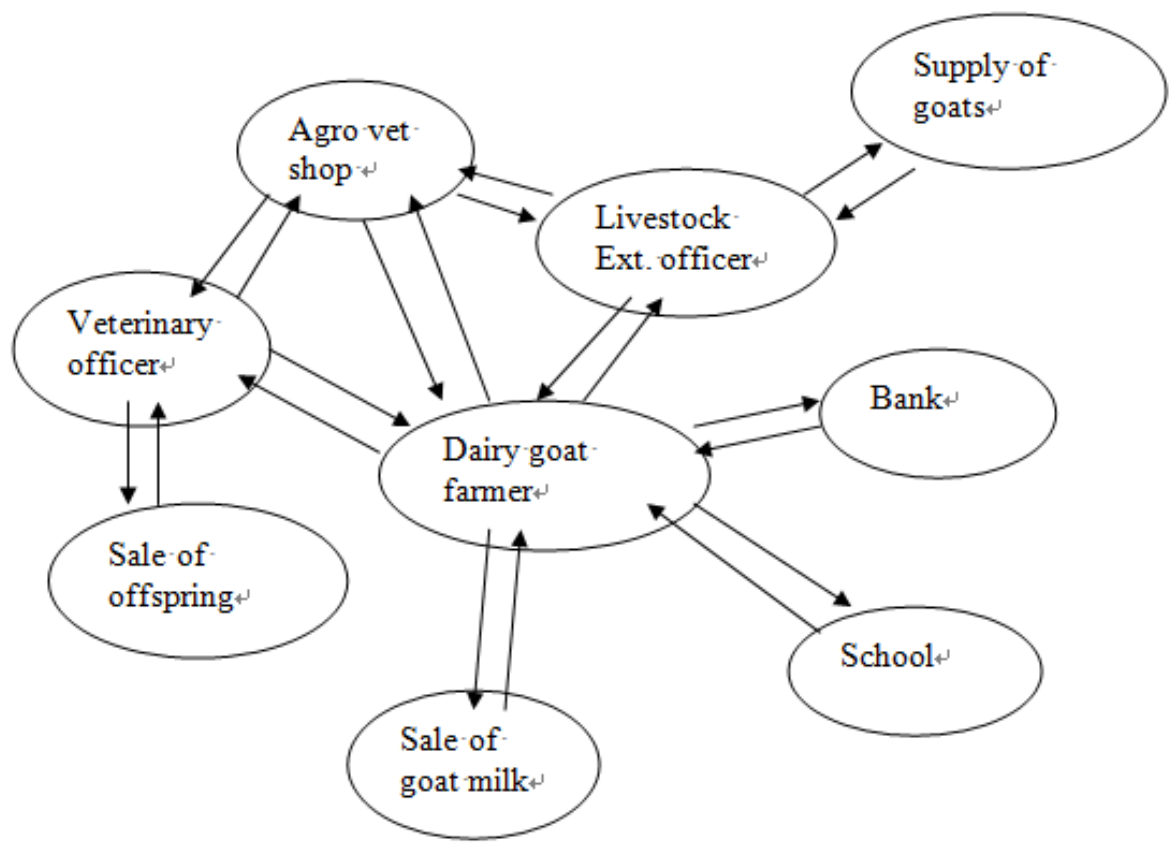

Figure 1. Conceptual framework (Source; authors) 
Adoption as a process starts with innovators, people who are ready to take risks and try their hands on new technologies. Mobile owners are people who spared part of their resources to keep up with the technology. They are likely to be ahead of others and even influence them. Innovators are known for their willingness to share information and influence innovations. Rogers defines an innovation as "an idea, practice, or object that is perceived as new by an individual or other unit of adoption".

\section{Materials and Methods}

\subsection{Study Area}

The study area was Kitui County in the Eastern region of Kenya. Kitui County is surrounded by seven counties: Machakos and Makueni to the west, Tharaka Nithi and Meru to the north, TaitaTaveta to the south, Embu to the northwest and Tana River to the east and southeast [6]. The County's population was $1,012,709$ in 2009 [7].

\subsection{Sampling Framework}

Key Informants Interviews (KIIs) were purposively sampled from people expected to have knowledge on the project or had perceived level of influence. Key Informants Interviews were conducted to World Vision Livestock Extension Officer, District Livestock Production Officer and District Veterinary Officer.

Sample size was calculated using Cochran formulae [8]:

$$
\mathrm{n}=\frac{\mathrm{z}^{2} \text { p.q. } \mathrm{N}}{e^{2}(\mathrm{~N}-1)+z^{2} \mathrm{p} \cdot \mathrm{q}}
$$

Where $\mathrm{z}$ (confidence interval) is at $90 \%$

$$
\begin{gathered}
\text { e (acceptable error }) \text { is }+(-) 10= \\
\frac{1.96^{2}(0.5)(0.5)(300)}{(0.1)^{2}(299)+(1.96)^{2}(0.5)(0.5)}=72.9
\end{gathered}
$$

This was revised to 100 for ease of distribution in the clusters and work of enumerators to collect a sizeable data in view of the fact that the data being collected is largely heterogeneous.

Sampling was then done in two stages i.e. proportional and random sampling within a cluster.

In proportional sampling, each administrative location was allocated a number according to that of its surviving farmers of dairy goats. Survey clusters were however formed depending on the proximity of the areas from one another and did not necessarily follow the administrative boundaries. A cluster consisted of an area to be visited by one enumerator who was expected to interview a total of 20 farmers.

\subsection{Data Collection and Analysis}

This exercise was conducted using household questionnaire by five enumerators, Key informant interviews
(KII) and Focus Group Discussions (FGD) integrated with relevant data collection approaches such as literature review and observation among other methods. A questionnaire was administered to 100 farmers sampled from a frame of 300 farmers who benefited from dairy goats supplied by Mutonguni Poverty Reduction Project (MPRP) in the year 2007. Two focused group discussions were held at two different clusters. One FGD was attended by 12 women in Kaimu cluster and the other one was attended by 13 men in Kakeani cluster. Both discussions were facilitated by the researcher with help of a recorder and an observer. The survey clusters are equivalent of administrative locations. Three KIIs were held with Livestock Officer of Mutonguni IPA, District Veterinary Officer, District Livestock Officer and Chairman of Kitui West Dairy Goat Association who provided very key information to corroborate what was gathered through other methods of data collection. Training content included objective of the survey, sampling methodologies employed and discussion of the questionnaire to be used during the exercise. The enumerators translated the questions in their mother tongue, (Kikamba) so that they had a common understanding of the questions. Every enumerator was assigned 20 farmers to interview. Focused Group Discussions (FGDs) was to help identify positive deviants and support the questionnaire responses by providing the qualitative data, as well as a means of triangulation. In special cases, when dealing with sensitive areas, a combination of approaches was applied to help get the response to sensitive questions, and strengthened the research ethics of the evaluation process.

This was both descriptive and inferential. Descriptive analysis provided profiles of dairy goat farmers on their ownership or access to mobile phones, frequency of use of those mobile phones to communicate to their customers, fellow group members and with the service providers. It also portrayed the rating of usefulness of mobile phone by different farmers and various challenges they face as they go about making calls and receiving and sending money through the mobile phone service.

\section{Results}

Most of the farmers under the project were women at $71 \%$ against men who form $29 \%$ of the farmers as shown in table 1.

Table 1. Goat farmers by gender

\begin{tabular}{|c|c|}
\hline Gender & Percentage (\%) \\
\hline Male & 29 \\
\hline Female & 71 \\
\hline Total & 100 \\
\hline
\end{tabular}

A good percentage of farmers $35 \%$ have not received formal education. $65 \%$ of farmers have attained either primary or secondary education as in Table 2, an 
improvement from the situation in 2009 when the indiactor was 53\% (MPRP mid-term evaluation report, 2009). Non of the farmers interviewed went beyond seconadry school. The high illiteracy level $(35 \%)$ has however not prevented the farmers from acquiring own mobile phone handsets $(70 \%)$, and even those who do not have their own usually rely on their family members or neighbors to communicate with fellow farmers and other stakeholders.

Table 2. Level of education of goat farmers

\begin{tabular}{|c|c|}
\hline Level of education of goat farmers & Percentage (\%) \\
\hline Never gone to school & 35 \\
\hline Primary Education & 47 \\
\hline Secondary Education & 18 \\
\hline Post Secondary Education & 0 \\
\hline Total & 100 \\
\hline
\end{tabular}

Table 3 shows that $47 \%$ of farmers with 3 goats and below report that they usually dispose of male offsprings to earn income and also to avoid in breeding. Disposal of animals and rotation of the breeding buck and arranging for buyers was done by use of mobile phone. A typical group breeding buck is shown in Figure 2

Table 3. Number of Dairy goats per Farmer

\begin{tabular}{|c|c|}
\hline Number of Dairy goats per Farmer & Percentage (\%) \\
\hline Famers having $1-3$ goats & 47 \\
\hline Farmers having 4 goats and above & 53 \\
\hline Total & 100 \\
\hline
\end{tabular}

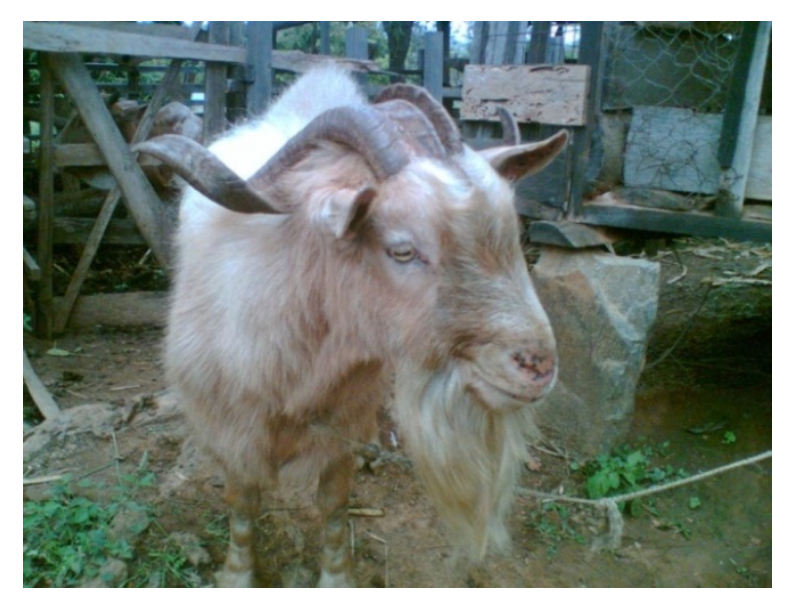

Figure 2. Group breeding buck

Table 4. Use of goat milk by farmers

\begin{tabular}{|c|c|}
\hline Use of Goat Milk & Percentage (\%) \\
\hline Never milked & 4 \\
\hline Family Consumption only & 42 \\
\hline Sale only & 0 \\
\hline Family Consumption and sale & 54 \\
\hline Total & 100 \\
\hline
\end{tabular}

The few farmers who have not been able to milk their goats lost the original stock to diseases and had to look for replacement on their own. They are also to be found in the less potential part of the catchment. Almost half the farmers (42\%) use milk from their dairy goats for home consumption to improve family nutrition.

The farmers who do not offer any milk for sale (46\%) are the same ones who consume all their milk in the family,as seen in table 5 . While $96 \%$ of farmers use milk in their families and sell to their neighbours. The demand of goat milk within the farm and its neighbourhood is so high that nothing is sold to institutions, even though, Muthale Hospital, among other institutions, offers ready market for goat milk. Goat milk is popular for boosting immunity of people living with HIV and AIDS. Esteemed buyers place their orders of milk by use of their mobile phones. According to mid-term evaluation of the project in the year 2009, milk was sold to neighbours at an average price of KES0.60 per litre. The average litre per household was 0.62 , while that sold to neighbours was 0.12 . Average price or mean per litre per household was 8.97. Income from the sale of goat milk was 151.80 per household. $36 \%$ of the 133 households indicated that they consume 1 litre of milk per day while $10.5 \%$ consumed 2 litres. Those who mentioned 3 litres were 1.5\%. The nearest market to sell the milk produced was Kabati about 2-7 km from the member groups. This trend of selling milk to neighbours as a preferred outlet has persisted.

Table 5. Milk for sale outlets

\begin{tabular}{|c|c|}
\hline Sale out let/market of milk & Percent \\
\hline Dont sell milk & 46.0 \\
\hline Sell milk to neighbours & 50.0 \\
\hline Sell goat milk in trading center & 4.0 \\
\hline Sell goat milk in institution & 00 \\
\hline Total & 100.0 \\
\hline
\end{tabular}

Table 6 shows that $99 \%$ of farmers interviewed either own mobile phones or have access to one whenever they need to communicate. This high percenatge shows the extent to which mobile phone technology has infiltrated the rearing of dairy goats in Kitui.

Table 6. Mobile phone ownership or access

\begin{tabular}{|c|c|}
\hline Mobile phone ownership or access & Percentage (\%) \\
\hline Own no mobile phone & 1 \\
\hline Own mobile phone & 70 \\
\hline Have access to mobile phone & 29 \\
\hline Total & 100 \\
\hline
\end{tabular}

In Table 7, eighty six percent of farmers have had their mobile phones long enough to influence their communication in the business of dairy goat rearing, Those who have used mobile phones for between 1-2 years disclose that they were being left whenever information was circulated by short message service (sms). 
Table 7. Duration of mobile phone use

\begin{tabular}{|c|c|}
\hline Duration of mobile phone use & Percentage (\%) \\
\hline Has never used mobile phone & 51 \\
\hline Used mobile phone for 3 years and above & 35 \\
\hline Has used mobile phone for between 1-2 years & 13 \\
\hline Has used mobile phone less than 1 year & 100 \\
\hline Total & 11 \\
\hline
\end{tabular}

Sixty nine percent of farmers mostly called Livestock extension officer and Veterinary officer (Table 8), both of whom are instrumental in the general management and disease control of the dairy goats. Twenty five percent of farmers called agrovet stores to inquire on drugs for controlling intestinal parasites and also to place orders for feed supplements for lactating goats.

Table 8. People called by mobile phone

\begin{tabular}{|c|c|}
\hline People called by mobile phone & Percentage (\%) \\
\hline Has never called any one & 1 \\
\hline Called extension officer & 26 \\
\hline Called veterinary officer & 43 \\
\hline Called agrovet stores & 25 \\
\hline Called customers of milk or goat & 5 \\
\hline Total & 100 \\
\hline
\end{tabular}

The District Veterinary Officer reported that on several occasions he was informed of goats that were sick through mobile phone and he responded promptly. In unfortunate situations when he received the information late, the animal succumbed but he still had to arrive and diagnose what caused death of the animal. The post mortem reports generated helped to develop mitigation measures against the diseases.

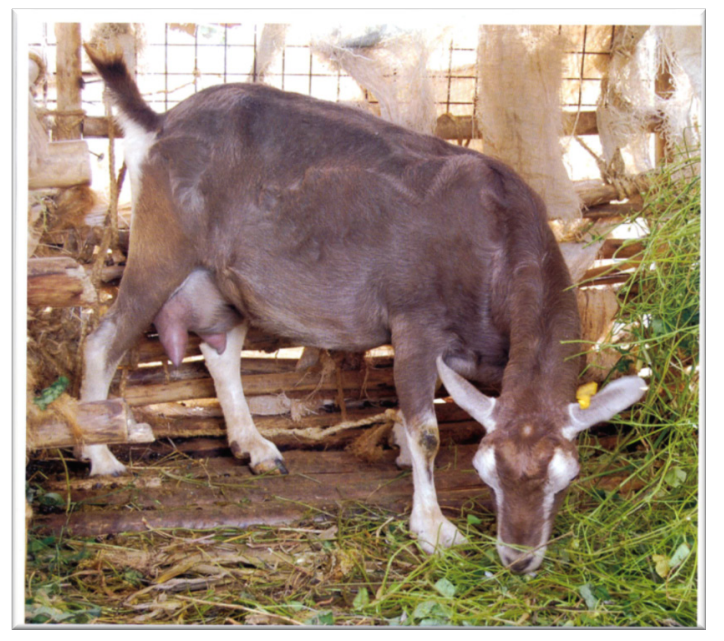

Figure 3. A well-managed dairy goat in Kitui

A well managed dairy goat is shown in Figure 3. Fifty seven percent of farmers communicate at least once every week over mobile phone, to members of dairy goat keeping group (Table 9).

Table 9. Frequency of mobile phone communication

\begin{tabular}{|c|c|c|}
\hline $\begin{array}{c}\text { Freq. of mobile phone } \\
\text { communication }\end{array}$ & Frequency & $\begin{array}{c}\text { Percentage } \\
(\%)\end{array}$ \\
\hline No communication & 1 & 1 \\
\hline Communicates daily & 9 & 9 \\
\hline Communicates twice a week & 11 & 11 \\
\hline Communicates weekly & 37 & 37 \\
\hline Communicates monthly & 42 & 42 \\
\hline Total & 100 & 100 \\
\hline
\end{tabular}

This was beside the communication that they make to other targets in respect to keeping of dairy goats. The high monthly communication $42 \%$, is when members are invited to monthly group meetings or when they inquire about the meetings. Ninety six percent of farmers were aware of mobile phone money transfer. This level of awareness has enhanced the transfer of money between farmers as well as with those outside the project.

Upto $95 \%$ of these farmers use mobile phone money transfer service at least once in a month, to send or receive money from members of the family, members of dairy goat association or from other sources. They reveal that delivery from agrovets that demand payment before delivery of drugs has been instant once they receive their payment through Mpesa service.. Misappropriation of group funds is reduced since the money is sent directly from a member to the treasurer without passing through other hands.

The most popular use of mobile money transfer service, $65 \%$ was when members make payments of the monies they owe to the group in terms of dues. This has greatly reduced defaulting by members and improved the groups monthly collection of money. The financial strength of the group is tranlated into proper management of group activitie like periodic meetings and organized capacity building sessions on the identified gaps. The second popular use of mobile money tranfer was to receive payment for goat milk that has been supplied. Payment at the end of the month is preferred by the milk suppliers as the money received is substantial and can be spent on a much worthy cause. 'Little money received every day immediately disappears into the kitchen', laments one farmer.

In a focused group discussion with KitheoNzao of Kakeani, It was pointed out that on several occasions members paid their dues to the respective groups through Mpesa service. Some secondary schools accepted payment through mobile money transfer which allowed the farmer to pay school fees without leaving his farm. While in the farm he continues to attend to the goats by fetching more feeds for the coming days.Sixty nine percent of farmers agreed that mobile phone is a very useful gadget and they have seen its fruits in their lives as keepers of dairy goats. $30 \%$ described the technology as either useful or fairly useful whereas one percent had no idea as to the usefulness of mobile phone technology.Those who find it very useful have used it to 
communicate to members through voice call or by way of sms service and also to send and receive money to various destinations.

No innovation comes without its challenges. $99 \%$ of farmers were able to cite one or a combination of challenges that they face as they use mobile phone in carrying out their business of keeping of dairy goats. Top on the list is high cost of airtime* at $32 \%$. This is followed closely by inadequate knowledge on use of mobile phones, which limits the number of features that a farmer can put to use on his/her mobile phone. Those who cite high cost of airtime, inadequate knowledge on use of mobile phone or both form $79 \%$ of the farmers, confirming that there is a burning dsire among the farmers to exploit the technology for increased dairy goat production.

1) Note * Airtime is currently priced friendly due to the intense competition among the mobile providers [11]

\section{Discussion}

By understanding and documenting the contribution of mobile phones to rate of diffusion of rearing of dairy goats in Kitui County, the study offers significant contribution to the development of dairy goat rearing in Eastern province and the adjoining areas. This will also be useful in the design of monitoring and evaluation frameworks that take into account the contribution of mobile phones to success of the project.

The dairy goat farmers of Kitui were selected on the basis of need. Rich farmers were left out and they are now the ones who have come up to acquire the goat breeds through their own efforts, having gauged the advantages of the project. They also do so with intention of supplying the Nairobi market where a litre of goat milk goes for about Ksh 300 . Sharing of information among fellow goat keepers is much easier and encourages triability. When a farmer sees it being done by a neighbor he gets challenged. This fits very well with Rodger's principle of homophily. Rogers defines homophily as "the degree to which pairs of individuals who interact are similar in certain attributes, such as beliefs, education, social status, and the like". When given the choice, individuals usually choose to interact with someone similar to him or herself. Furthermore, homophilous individuals engage in more effective communication because their similarities lead to greater knowledge gain as well as attitude or behavior change.

The situation in Kitui presents similarities as well as differences witnessed in Uganda. Kitui dairy goat farmers consulted with experts on livestock management practices more than the proportion of Ugandan farmers who consult the experts. Unlike Kitui farmers Uganda farmers were able to undertake such specialized tasks like, taking photos of agricultural demonstrations, using the loudspeaker function to permit a group of farmers to consult with an expert, recording group members pledging when they will repay loans, and storing data such as the date hens should start laying eggs. The low numerical literacy level among Uganda women that affected their use of calculator features of the mobile phone is not a serious problem in Kitui. Martin and Abott [8] conducted research in Uganda to evaluate the relationship between level of education completed and length of time owning the mobile phone under the assumption that those who are higher in education level would have adopted the mobile phone earlier. This was also noted with Kitui farmers about their educational levels.

In Nigeria, studies done by Bolarinwa et al.[9] in 2011 showed that extension agencies can adequately serve the farmers with needed agricultural information in case ICT component such as mobile phone are employed alongside television and radio. The report concluded that there will be quick exchange of agricultural information between the extension agents and farmers if ICT components are integrated in delivery of agricultural information to farmers in Nigeria. In the same vein, extension agents will relay farmers' information needs to researchers and rapidly access large amount of information from the researchers through mobile phone for onward dissemination to farmers.

This position has been corroborated by the high proportion of Kitui dairy goat farmers who engage the experts to exchange agricultuarl information on management of dairy goats and control of diseases. Farmers communicate with agrovet stores to procure feede supplements and to negotiate for market for their products. In the same breathe the importance of mobile phone among partners of the farmer cannot be overemphasized.

It was deduced from this finding that income status of the households, affected the attainment of food and nutrition security. Hence living standard of the cell phone users cannot be compared with non phone users.

\section{Conclusions and Recommendation}

The role played by mobile in agricultural production can no longer be ignored. The aspect of mobile phone communication must be embedded in the programming of the projects. Challenges notwithstanding, the technology has shaped the dairy goat keeping technolgy to a great extent in Kitui County. The result is improved family nutrition and household income. The higher percetage of farmers who offer part of their milk for sale confirms that the amount of goat milk produced often surpass the family milk demand. The County Ministry of Agriculture Livestock and Fisheries should embrace technology and give mobile phones to their extension staff to reach the farmers. We recommend that public/development agents who design agricultural projects should include aspect of mobile phone communication; gadgets and capacity building to enhance farmer communications with other stakeholders.

\section{Acknowledgements}

We thank all the respondents and stakeholders in Kitui 
County for their participation in this study. The first author funded this research as part of his Masters' thesis in Agricultural Information Communication Management. We are grateful to late Dr. Mugivane's comments and the logistic support from World Vision staff.

\section{REFERENCES}

[1] Aker C. Jenny. (2010), Dial "A" for Agriculture: Using Information and Communication Technologies for Agricultural Extension in Developing Countries. Tufts University

[2] Mbiti and Aker. (2010) Mobile phones and economic development in Africa. Journal of Economic Perspectives 24 (3) pp 207-232

[3] World Vision (2007). World Vision International, Nairobi

[4] Rogers, Everett M. (2003).Diffusion of Innovations (Fifth Edition). New York: The Free Press.

[5] Rogers, Everett M. with Shoemaker, Floyd. (1971). Communication of Innovations. New York: The Free Press.

[6] GoK (2013). Survey Department, Government of Kenya, Government Press, Nairobi.

[7] KNBS (2009). Kenya National Bureau of Statistics,

[8] Cochran W. G. (1963). Sampling Techniques, 2nd Ed., New York: John Wiley and Sons, Inc.

[9] Martin, B and Abbott, E. (2008), Development Calling: The Use of Mobile Phones in Agriculture Development in Uganda.

[10] Bolarinwa, K. K., and Oyeyinka, R. A. (2011). Use of Cell Phone by farmers and its implication on farmers' production capacity in Oyo State Nigeria.

[11] CA. 2016. Communication Authority of Kenya. Nairobi, Kenya. 